\title{
Application of Multiparameter Method as an Assistance to the Evaluation of the Need for Replacement of Medical Equipment
}

\author{
By M. A. Marciano' and E. K. Souza ${ }^{2}$ \\ ${ }^{1}$ Moinhos de Vento Hospital/Clinical and Hospital Engineering, Porto Alegre, Brasil \\ ${ }^{2}$ Moinhos de Vento Hospital/Clinical Engineering, Porto Alegre, Brasil
}

\begin{abstract}
Medical equipment is an increasingly important element in modern medicine and medical and hospital care. For medical equipment to contribute effectively and productively to health organizations, it is necessary to carry out the management of their life cycle. A decisive factor in this life cycle is to know when a piece of equipment must be replaced. It is observed that defined and clear methods must be in place to assist the clinical engineering and hospital management in deciding and prioritizing which medical equipment needs to be replaced and when. This work has a practical application in the management of the medical equipment inventory. As a result, the classification of medical equipment and the prioritization of substitution is obtained concerning variety, quantity, and cost of the equipment to be replaced. The application of this method may contribute to the increased quality of the installed equipment and effective budget planning for hospital investments.
\end{abstract}

\section{Keywords - Prioritization replacement, multiparameter method, Biomedical equipment.}

Copyright (C) 2021. This is an open-access article distributed under the terms of the Creative Commons Attribution License (CC BY): Creative Commons - Attribution 4.0 International - CC BY 4.0. The use, distribution or reproduction in other forums is permitted, provided the original author(s) and the copyright owner(s) are credited and that the original publication in this journal is cited, in accordance with accepted academic practice. No use, distribution or reproduction is permitted which does not comply with these terms.

\section{INTRODUCTION}

Medical equipment is increasingly important in modern medicine to aid in research, diagnosis, monitoring, therapy, and life support of human beings in need of medical and hospital care. Hospitals, in turn, have become sophisticated centers of technology. ${ }^{1}$ The inappropriate use of technology may put users and the effectiveness of health organizations at risk. For medical equipment to contribute effectively and for health organizations to use them more productively, there is a need to manage their life cycle. The equipment's life cycle is divided into phases, in the following sequence: Innovation, Initial Diffusion, Incorporation, Large-Scale Use, and Renouncement/ Substitution. ${ }^{2}$
A key factor in this life cycle is knowing when any medical equipment should be replaced (to avoid inefficiency, unavailability, risks to patients, etc.). Other reasons for replacement need may be high operation cost, obsolescence, or inadequacy in meeting demand. ${ }^{3}$ The equipment can be classified into two groups, those with decreasing efficiency and a predictable useful life (with low equity options without replacement, low with replacement by same type equipment, and low with replacement by more efficient equipment), and those with constant efficiency and unpredictable useful life. ${ }^{3}$ As there is a historical scarcity of financial resources in healthcare an increasing, rational allocation of this resource is vital. Therefore 
studies, methodologies development, and tools to define the cost of a technology's useful life are increasingly valued to avoid those subjective criteria being used in the decision-making process. ${ }^{4}$

For some factors, such as which technologies tend to be cumulative rather than substitutive, it is complex to define obsolescence criteria for medical technology. ${ }^{5}$ In view of such complexity, it is observed there is an absence of clear and defined methods in the literature, as well as the application of methods and criteria to assist clinical engineering and hospital management in deciding which medical equipment needs to be replaced.

This study presents an alternative method, practical application and has the main objective to present a classification of medical equipment regarding replacement priorization as a consequence of obsolescence, evaluation of the technological medical equipment in use in the hospital, and to assist with direction in the variety, quantity, and costs of medical equipment needing replacement according to obsolescence criteria. The method used in this practical application was the Multiparameter developed in 1992 and applied for the first time at St. Luke Medical Center to a range of five different types of equipment, such as intra-aortic balloon, ECG, defibrillator, neonatal incubator, and ergometric treadmill, totaling 146 pieces of equipment. ${ }^{6}$ The option for this method was to understand that it covers a variety of parameters and attributes, from technical, economic-financial and medical-assistance points of view. In the evaluation of the medical equipment life cycle, the importance of the observation by the prism of manufacturer and medical-care user is relevant. ${ }^{7}$ This proposed method has a clear and objective formulation and allows applying to a variety and quantity of medical equipment, which is one of the assumptions of this work. Because it is composed of quantitative and qualitative attributes, and thus a wide coverage of the evaluation criteria, the application becomes attractive in relating practice and experience with actual data. ${ }^{8}$ The application of this method can contribute to an increase in the quality of the management of medical equipment installed and with the investment planning of the hospital budget. This demonstrates that the knowledge acquired and developed by frequent research from clinical engineering professionals and the disseminated practical application can contribute to the decisions of health organizations' management and thus add value in a more meaningful way because well-prepared professionals are essential to guide the decisions of health organizations. ${ }^{5}$

\section{MATERIALS AND METHOD}

The applied method considers four groups of parameters to compose the plots of the equation denominated RPV (Replacement Priority Value), being: technical (contributing with $40 \%$ in the equation), criticality (contributing $20 \%$ ), financial-economic (contributing 20\%), and clinical parameters (contributing 20\%). One of the prerequisites for this application is to have the information about the medical equipment inventory to be analyzed, as well as the maintenance history of each one.

The first group mentioned, shown in Table 1, is composed of four attributes related to equipment: the age, maintenance cost (in this study, the maintenance cost [MC] was adapted to $24 \%$ according to the Brazilian reality, since in the original study the MC reference is $15 \%$, considering the last 3 years regarding the purchase value), stopping time, and end of manufacturer support. In the four attributes, if the analyzed medical equipment has a good classification it receives a zero score, otherwise, it receives 1 . Limits are described in Table 1.

TABLE 1. Technical Parameters

\begin{tabular}{|c|c|}
\hline Criteria & Scoring Rule \\
\hline Technical Criteria & $\mathrm{MAN}=$ Age $+\mathrm{MC}+\mathrm{ST}+\mathrm{MS}$ \\
\hline \multirow{2}{*}{ Age (Age) } & Age $\geq 7$ years $=1$ \\
\hline & Age $<7$ years $=0$ \\
\hline \multirow{2}{*}{$\begin{array}{l}\text { Maintenance Cost } \\
\text { (MC) }\end{array}$} & $\mathrm{MC} \geq 24 \%$ New equipment $=1$ \\
\hline & $\mathrm{CM}<24 \%$ New equipment $=0$ \\
\hline \multirow{2}{*}{ Stopping Time (ST) } & $\mathrm{ST} \geq$ Average group break time $=1$ \\
\hline & $\mathrm{ST}<$ Average group break time $=0$ \\
\hline \multirow{2}{*}{$\begin{array}{l}\text { End of Manufacturer } \\
\text { Support (MS) }\end{array}$} & $\begin{array}{c}\text { MS }=1 \text {, when spare parts are available } \\
\text { on the market }\end{array}$ \\
\hline & MS $=0$, when spare parts are not \\
\hline
\end{tabular}


The age of the equipment was considered using data provided by the accounting sector of the institution. The MC and stopping time of the equipment were acquired through the asset management software. For the end of manufacturer support criteria, the formal communication issued by manufacturers was used as a reference.

The second group mentioned, as shown in Table 2, is composed of a single attribute, which is the function of the equipment. In this attribute, the medical equipment is framed in one of four classifications, according to the function, as shown in Table 2 . In relation to criticality, the equipment was classified according to its application/ function.

TABLE 2. EM Criticality

\begin{tabular}{|l|c|}
\hline Criteria & Scoring Rule \\
\hline $\begin{array}{l}\text { Medical equipment } \\
\text { criticality (FUN) }\end{array}$ & FUN \\
\hline Life support & FUN $=4$ \\
\hline Therapy & FUN $=3$ \\
\hline $\begin{array}{l}\text { Diagnosis/ } \\
\text { monitoring }\end{array}$ & FUN $=2$ \\
\hline $\begin{array}{l}\text { Analysis / support / } \\
\text { assistant }\end{array}$ & FUN $=1$ \\
\hline
\end{tabular}

The third group, shown in Table 3, is composed of two attributes, one is the increase of billing and the other is the reduction of cost. In the two attributes, if the replacement of the medical equipment analyzed results in increased billing or cost reduction, it receives a score of 1 .

TABLE 3. Financial-Economic Parameters

\begin{tabular}{|l|c|}
\hline Criteria & Scoring Rule \\
\hline $\begin{array}{l}\text { Financial-Economic } \\
\text { Parameters }\end{array}$ & Cost Benefit $(\mathrm{CB})=\mathrm{IB}+\mathrm{CR}$ \\
\hline \multirow{2}{*}{ Increased Billing (IB) } & $\begin{array}{c}\mathrm{IB}=1, \text { if the replacement equipment } \\
\text { provides a higher billing }\end{array}$ \\
\cline { 2 - 2 } & $\begin{array}{c}\mathrm{IB}=0 \text {, if the replacement equipment } \\
\text { does not provide a higher billing }\end{array}$ \\
\hline
\end{tabular}

\begin{tabular}{|c|c|}
\hline \multirow{1}{*}{ Cost Reduction (CR) } & $\begin{array}{c}\mathrm{CR}=1, \text { if the replacement equipment } \\
\text { provides a reduction in the cost of } \\
\text { operation and/or maintenance }\end{array}$ \\
\cline { 2 - 3 } & $\begin{array}{c}\mathrm{CR}=0 \text {, if the replacement equipment } \\
\text { does not provide a reduction in the } \\
\text { cost } \\
\text { of operation and/or maintenance }\end{array}$ \\
\hline
\end{tabular}

To classify or score the equipment in the financialeconomic parameter, it was necessary to know by which technology the equipment under analysis could be replaced. And, also be aware whether the replacement could bring cost reduction or increased billing. If positive, the score of each of the two mentioned attributes would be 1 (Table 4).

TABLE 4. Clinical-Safety Parameters

\begin{tabular}{|c|c|}
\hline Criteria & Scoring Rule \\
\hline $\begin{array}{l}\text { Clinical Parameters } \\
\text { and Safety }\end{array}$ & $\begin{array}{c}\text { Clinical efficacy and preference (CEP) } \\
\qquad \mathrm{CEP}=\mathrm{IT}+\mathrm{UP}+\mathrm{IS}\end{array}$ \\
\hline \multirow{2}{*}{$\begin{array}{l}\text { Improvement in } \\
\text { treatment (IT) }\end{array}$} & $\begin{array}{c}\text { IT }=1, \text { if EM offers improvement in } \\
\text { the treatment }\end{array}$ \\
\hline & $\begin{array}{l}\mathrm{MT}=0 \text {, if EM doesn't offer } \\
\text { improvement in the treatment }\end{array}$ \\
\hline \multirow{3}{*}{ User preference (UP) } & $\begin{array}{l}\mathrm{UP}=2 \text {, if the user preference for } \\
\text { exchanging equipment is large }\end{array}$ \\
\hline & $\begin{array}{c}\mathrm{UP}=1 \text {, if the user preference is } \\
\text { medium }\end{array}$ \\
\hline & $\begin{array}{c}\mathrm{UP}=0 \text {, if there is no preference for } \\
\text { exchange }\end{array}$ \\
\hline \multirow{2}{*}{$\begin{array}{l}\text { Increased } \\
\text { standardization (IS) }\end{array}$} & $\begin{array}{c}\text { IS }=1, \text { if the replacement equipment } \\
\text { provides increased standardization } \\
\text { among medical equipment }\end{array}$ \\
\hline & $\begin{array}{c}\text { IS }=0 \text {, if the replacement equipment } \\
\text { doesn't increase standardization } \\
\text { among medical equipment }\end{array}$ \\
\hline
\end{tabular}

In this parameter group, it was necessary to know if the equipment replacement in the evaluation could be more efficient, to increase the standardization, or to have increased user preference. This classification was conducted with the support of care managers and doctors from the areas in which the analyzed equipment were allocated. 
After completing all the parameters listed, the following formula was applied to obtain a final score, called Replacement Priority Value (RPV). This formula considers a weight or percentage for each group of parameters evaluated.

$\mathrm{RPV}=0,4 .+0,2 .+0,2 .+0,2 .(1)$

To support the classification of Replacement Prioritization there is a decision scale in this method, as shown in Table 5.

TABLE 5. Classification of Replacement Priorization

\begin{tabular}{|l|c|}
\hline Criteria & Scoring Rule \\
\hline Keep in operation & $\mathrm{RPV}<1$ \\
\hline $\begin{array}{l}\text { Reevaluate the } \\
\text { condition of the } \\
\text { equipment in the } \\
\text { next } 12 \text { months }\end{array}$ & $1 \leq \mathrm{RPV} \leq 1,2$ \\
\hline $\begin{array}{l}\text { Replace in the next } \\
24 \text { months }\end{array}$ & $1,3 \leq \mathrm{RPV} \leq 1,6$ \\
\hline $\begin{array}{l}\text { Replace in the next } \\
12 \text { months }\end{array}$ & $\mathrm{RPV} \geq 1,7$ \\
\hline
\end{tabular}

A spreadsheet was used as a tool to apply this method in a private, non-profit hospital with approximately 400 beds and an installed base of approximately 4,500 medical equipment.

\section{RESULTS}

Through the application of the Multiparametric Method, it was possible to know and visualize an overview of the replacement, which equipment should be kept in operation without any restriction, and how many should be kept in operation but with a reevaluation in the next 12 months (81 pieces of equipment) and 24 months (164 pieces of equipment), as shown in Figure 1.

It was also possible to identify which types and quantities of equipment should be prioritized, visualize the diversity prioritized by cost center, and provide management with an estimate of the financial resources needed to invest in replacements.
FIGURE 1. Overview of the replacement.

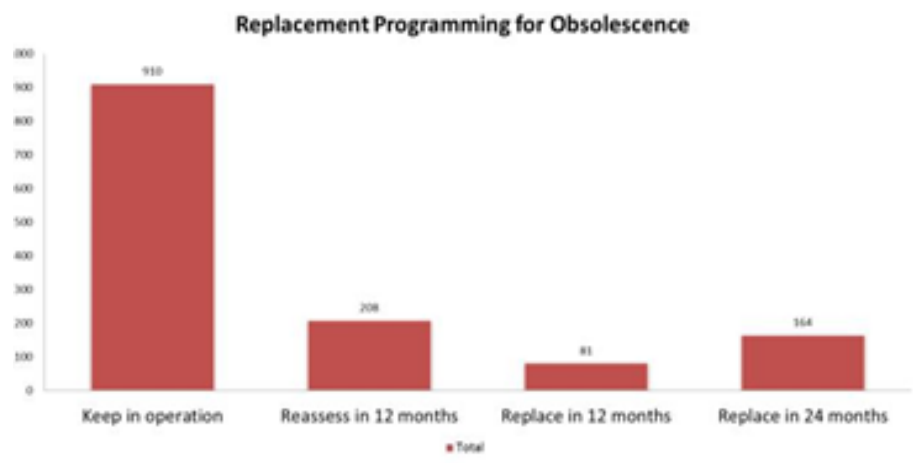

Another possible analysis was the verification of the partial classification referring to the groups of clinical, financial, economic, and technical parameters that determined if it was graduated with a partial result. This prism of analysis assists in the understanding of under which parameters certain equipment is worse qualified.

\section{DISCUSSION}

Health organizations, through clinical engineering services, need to have effective control of the medical equipment they own. The use of medical equipment life-cycle management software allows us to record all maintenance history. Knowledge of this data and information are a prerequisite for using technology evaluation methods.

The Multiparametric Method, with the range of criteria demonstrated, may be a practical alternative when evaluating the Replacement Prioritization of a wide range of medical equipment types. The continuity of application of this method, adaptations of attributes, and way of applying (mainly subjective ones) are subject to refinement and adjustment. There is also a need to implement the results after modeling, simulation, and resolution of the equations and types of computational tools being used. Both the methods and results of this practical application were fully accepted by senior management, by the managers, coordinators, and the multi-professional team responsible for the evaluation of hospital investments.

The list of medical equipment with a priority of replacement, as a result of the evaluation of obsolescence of the 
inventory of the technology was the basis of the biomedical equipment investment sheet. Other medical equipment made the list but came from other hospital needs.

\section{CONCLUSION}

Clinical engineering services can increase the performance of this evaluation and propose plausible alternatives (appropriate, comprehensive, practical, etc.) to hospitals regarding the use of methods and criteria that allow indicating the appropriate timing and prioritization of equipment replacement. The use of these methods can contribute to the quality, availability, security, and performance of the technologies as well as aid in accounting for the costs related to the life cycle of the hospital medical equipment inventory which would help in the planning of the health institution investment.

Other types of methods also need to be developed, studied, analyzed, and applied in a larger variety of medical equipment (to evaluate which method is best applied to a certain class of equipment) and more widely in the health organizations, to contribute substantially to managing the life cycle of the medical equipment installed.

\section{CONFLICT OF INTEREST}

The authors declare that they have no conflict of interest.

\section{REFERENCES}

1. Bronzino JD The Biomedical Engineering Handbook. 2nd ed. USA: CRC Press, Inc; 2000.

2. Krauss-Silva L. Avaliação tecnológica em Saúde: questões metodológicas e operacionais. Caderno de Saúde Pública; 2006.

3. Brehm D0. Ponto 2: Metodologia e princípios da Análise de Investimentos; Análise de Projetos industriais e substituição de equipamentos; Prática instrumental, tabelas, planilhas e calculadoras Financeiras; 2012.

4. Stiefel R and Riskalla E. The elements of a complete product evaluation, Biomed Instrum Technol 1995 Nov-Dec;29(6):482-8.

5. Novaes HMD. Produções e avaliações de tecnologias dos sistemas de Saúde: desafios do século XXI. São Paulo 2006;40:133-40.

6. Fennigkoh L. Medical equipment replacement model. J Clin Eng 1992 Jan/Feb; 17(1): 43-47.

7. Santos F, Garcia R. Contribuição de metodologia para definição de substituição e incorporação de novas tecnologias na área da Saúde. II XII Jornadas Internationales de Inginieria Clínica y Tecnologia Médica (Entre Rios-Argentina). Anais. Argentina 2006;27-31.

8. Katz Z. Estudo de Metodologias Econômicas e Multiparamétricas Aplicadas à Decisão de Substituição de Equipamentos Médicos. Dissertação Mestrado em Engenharia Elétrica. FEE UNICAMP; 1998. 